Brazilian Journal

of Chemical

Engineering

\title{
CONVERSION OF SPENT FAT OIL INTO LIQUID AND GASEOUS FUELS THROUGH CLINKER CATALYZED PYROLYSIS
}

\author{
Z. Hussain ${ }^{1}$, H. Naz, M. Rafique ${ }^{2}$, H. Gulab ${ }^{3}$, M. Y. Naz ${ }^{4 *}$ \\ S. A. Sulaiman ${ }^{5}$ and K. M. Khan ${ }^{6}$ \\ ${ }^{1}$ Abdul Wali Khan University, Department of Chemistry, Mardan, Pakistan. ORCID: 0000-0002-2200-2555 \\ ${ }^{2}$ Quaid-I-Azam University, Department of Chemistry, Islamabad, Pakistan. ORCID: 0000-0002-2098-9114 \\ ${ }^{3}$ Bacha Khan University, Department of Chemistry, Charsada, Pakistan. ORCID: 0000-0002-7841-0355 \\ ${ }^{4}$ University of Agriculture, Department of Physics, 38040 Faisalabad, Pakistan. E-mail: yasin603@yahoo.com - ORCID: 0000-0002-8490-7819 \\ ${ }_{5}^{5}$ Universiti Teknologi Petronas, Department of Mechanical Engineering, Malaysia. ORCID: 0000-0001-8819-6703 \\ ${ }^{6}$ University of Karachi, H. E. J. Research Institute of Chemistry, Pakistan.
}

(Submitted: September 7, 2018 ; Revised: October 23, 2018 ; Accepted: November 26, 2018)

\begin{abstract}
Repeated heating of fat oil may result in the formation of highly toxic aldehyde compounds. The oils having such compounds are considered as health hazards and therefore their repeated use is banned in many countries. Since huge quantities of the used oil need urgent disposal, this work is focused on the disposal of used oil for the resource recovery. The waste fat oil was converted into useful fuel through catalytic and non-catalytic pyrolysis. The catalyst was used to lower the oxygen content and to increase the amount of the hydrocarbons in the oil product. The pyrolysis reaction was catalyzed by three catalysts of the clinker type, namely ordinary Portland cement, white cement and burnt clay/clinker powder. The pyrolysis reactions were performed using a custom-made furnace and stainless steel pyrolyzer. Optimum temperature, time and catalyst quantity were identified for high liquid and gaseous fractions and low solid residue. The oil obtained during each reaction was characterized for chemical composition by using GC-MS technique. The oil product of simple pyrolysis, cement catalyzed, white cement catalyzed and clinker catalyzed pyrolysis had the hydrocarbon contents of $3 \%, 19 \%$, $51 \%$ and $93 \%$, respectively.
\end{abstract}

Keywords: Waste cooking oil; Animal fat; Catalytic pyrolysis; Resource recovery; Clinkered catalyst.

\section{INTRODUCTION}

Huge quantities of a variety of wastes are produced around the world due to the tremendous increase in population and rapidly changing lifestyle (Hussain et al., 2016). The waste may come from industries or from the interaction of population and use of various materials. Both biodegradable and non-biodegradable wastes are generated as municipal waste or industrial waste. These wastes are a potential threat to human health if not treated properly (Ali et al., 2014). One of the best strategies for the waste disposal is its conversion into useful material through thermal, thermo-catalytic or biological means. Waste cooking oil is considered as one of the hazardous wastes. It is produced from cooking oil after repeated use. Cooking oil may pass through thermal degradation and thermo-catalytic oxidation during cooking and frying operations. When the concentration of oxidized products in the oil reaches $25 \%$ or more, it is reported as waste or spent oil. The use of such waste cooking oils is a health hazard and may be the cause of cancer (Kalam et al., 2011).

Both the vegetable oils and animal fats are triglycerides (Ali et al., 2014; Kalam et al., 2011). Fats and fat oils are solids or semi-solids compared

\footnotetext{
*Corresponding author: M. Y. Naz - E-mail: yasin603@yahoo.com
} 
to vegetable oil and have long-chain saturated alkyl moieties. Triglyceride is mostly used to cook and fry foods in addition to their use in preparation of soap. These are also converted into biodiesel by the transesterification process. However, the major utility of this oil is for cooking and frying. At present, the quantity of oil used for frying around the world exceeds 20 million tons (Hussain et al., 2016). Frying is carried out at as high a temperature as the boiling point of oils. The reaction of triglycerides with moisture and oxygen forms highly toxic aldehydes, which may cause cancer (Ali et al., 2014; Kalam et al., 2011). With repeated cooking raises the amount of these compounds. The repeated use of the same oil for frying is a potential hazard for human health. Repeated cooking and frying may also alter the oil's physical characteristics. These characteristics include colour, viscosity and smoke. To prevent the risk of toxicity, many countries around the world ban repeated use of oils and fats (Totani et al., 2006).

Large quantities of waste cooking oil are produced around the world, which are disposed by feeding to animals. However, the European Union prohibited animal feed in 2002 because of danger of returning the toxic chemicals to the food chain via animal meat (Kulkarni and Dalai, 2006). In addition to water pollution and damage to the ecosystem, waste disposal in drains and sewers can trigger blockage and esthetic issues. Due to the related environmental issues, disposal of waste cooking oil in landfills and sewage treatment is also not feasible. Large quantities of used cooking oil are dumped into rivers and landfills causing environmental pollution (Yang et al., 2007; Kalam et al., 2011). One possible way to deal with the issue is to recycle the waste cooking oil and convert it into biodiesel (Kulkarni and Dalai, 2006; Yang et al., 2007). However, this choice is less appealing due to the existence of big amounts of compounds other than triglycerides and a change in viscosity during repeated cooking.

One of the simplest and more productive options for the resource recovery from waste cooking oil is pyrolysis. Pyrolysis is the process of thermal decomposition of the waste in the absence or limited supply of air. Waste cooking oil can be converted into useful oil and gas through catalytic and noncatalytic pyrolysis (Souza et al., 2017; Buscato et al., 2018). Abdebanjo et al. (2005) converted lard into diesel-like fuel through pyrolysis. This fuel can also be obtained from vegetable oil. The pyrolysis of triglycerides may give a mixture of hydrocarbons and oxygenated compounds (Quirino et al., 2009). This work is focused on waste disposal, resource recovery and capability enhancement for sustainability and a pollution free environment. In this work, waste fat oil was converted into gasoline and diesel range fuel oil and combustible gas. This work was also focused on assessment of the catalytic activity of low-cost clinker catalyst for increasing the yield and selectivity of the oil product. The concentration of oxygenated compounds and hydrocarbons was increased through catalytic pyrolysis of the waste oil.

\section{MATERIALS AND METHODS}

The samples of the spent oil from animal fat were obtained from a restaurant in the Mardan district of Pakistan. Kabab is a famous food recipe, which is prepared by mixing ground meat with spices and maize flour. This recipe is normally cooked in oil of animal fat, which is usually solid at ambient temperature and oil on melting. The kabab sellers may also use the spent oil as fire initiator and fire promoter. The spent oil is a mixture of oils obtained from the fat of different animals. Solidified and waxy samples of the spent oil were blackish in color due to the hours of long cooking operations and some left-over ingredients of the kabab. The spent fat oil was used without further treatment.

\section{Catalyst Type}

Three catalysts were used to catalyze the reaction, namely cement, white cement and burnt brick powder. All the catalysts were the clinkered material. The cement catalyst was purchased from a local retailer of the Cherat cement factory, Pakistan. The white cement was purchased from the Mardan area of KPK Pakistan. The white cement was commercial grade cement of the Maple Leaf Factory Limited, Pakistan. The commercial grade cement catalysts had specific surface area in the range of $2989 \mathrm{~cm}^{2} / \mathrm{g}$ to $3035 \mathrm{~cm}^{2} / \mathrm{g}$. The burnt or vitrified brick is commonly named as clinker, which was obtained from a local kiln and crushed into powder followed by sieving through a 100 $\mu \mathrm{m}$ mesh. Using an X-ray fluorescence spectroscopy method, all the catalysts were screened for their chemical composition. The results of the study are given in Table 1.

Table 1. Chemical composition of the used catalysts.

\begin{tabular}{cccc}
\hline \multirow{2}{*}{ Chemical } & \multicolumn{3}{c}{ Concentration (\%) } \\
\cline { 2 - 4 } & Cement & $\begin{array}{c}\text { White } \\
\text { Cement }\end{array}$ & Clinker \\
\hline $\mathrm{SiO}_{2}$ & 21.25 & 21.71 & 55.237 \\
$\mathrm{Al}_{2} \mathrm{O}_{3}$ & 5.56 & 3.88 & 12.713 \\
$\mathrm{CaO}$ & 63.53 & 66.34 & 9.958 \\
$\mathrm{Fe}_{2} \mathrm{O}_{3}$ & 3.24 & 0.25 & 7.211 \\
$\mathrm{SO}_{3}$ & 2.55 & 2.95 & ---- \\
$\mathrm{MgO}$ & 2.1 & 0.66 & 2.908 \\
$\mathrm{Na}_{2} \mathrm{O}$ & 0.61 & 0.05 & 0.670 \\
$\mathrm{~K}_{2} \mathrm{O}$ & ----- & 0.57 & 1.991 \\
\hline
\end{tabular}




\section{Pyrolyzer Design}

The catalytic and non-catalytic pyrolysis of the spent fat oil were carried out using a stainless steel pyrolyzer. The pyrolysis reactor had a lid coupled with a $3.81 \mathrm{~cm}$ long side tube. The reactor's height was 14 $\mathrm{cm}$, while the inner diameter was $6.72 \mathrm{~cm}$. A custommade furnace coupled with a digital temperature controller was used in the presented work. The furnace was preheated to perform the pyrolysis experiments. The pyrolysis reactor was placed inside furnace. A schematic of the experimental setup is shown in Fig.1. It was a batch type stainless steel reactor.

The pyrolysis reactor was operated in a distillation mode. Glass tubes were used to connect the reactor with a condenser and cold traps. All the components were connected in series. Besides the cold traps, two additional traps were also connected in series to analyze the gaseous products. The condenser and cold traps were used to condense and trap the liquid product of pyrolysis. The vapors produced during pyrolysis were condensed in the cold traps and the gas product was absorbed to explore its chemical nature in the chemical traps. The gas product was also assessed with a miniature burner for its combustibility.

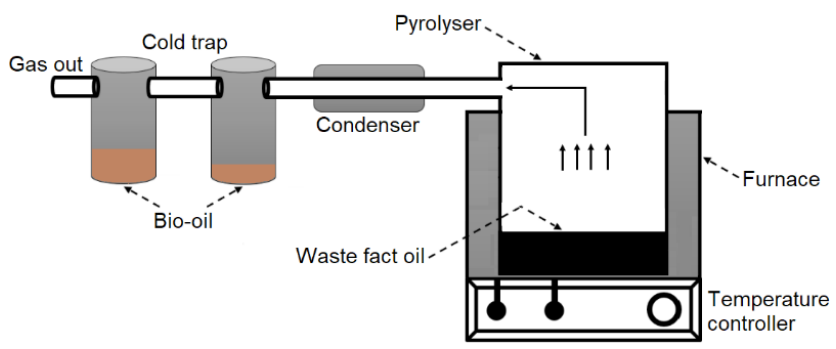

Figure 1. Schematic of the reaction assembly.

\section{GC-MS Analysis}

The catalytic and non-catalytic pyrolysis yielded a mixture of wax and oil, which can be seen by naked eye as suspended solids. Approximately, $0.1 \mathrm{~g}$ of the oil and wax blend was dissolved in $100 \mathrm{ml}$ of chloroform. The resulting solution was evaluated for its chemical composition by using a split type GC-MS instrument (Shimadzu, Japan; GCMS-QP2010). An auto injector (ADC-201) was installed in this instrument. The liquid product of pyrolysis was split into its components by passing through a DB-5MS column. For these analyzes, the carrier gas was helium, which was fed at a flowrate of $1.32 \mathrm{ml} / \mathrm{min}$. The sample was injected with an injector, which was adjusted at $300^{\circ} \mathrm{C}$. Initially, the temperature was held for $5 \mathrm{~min}$ at $35^{\circ} \mathrm{C}$ for $5 \mathrm{~min}$. Thereafter, furnace temperature was raised to $100^{\circ} \mathrm{C}$ at a rate of $5^{\circ} \mathrm{C} \mathrm{min}{ }^{-1}$ with hold time of $5 \mathrm{~min}$. In next step, furnace temperature was raised to $150^{\circ} \mathrm{C}$ at a rate of $10^{\circ} \mathrm{C} \mathrm{m^{-1 }}$ and maintained for $10 \mathrm{~min}$. Finally, the temperature was raised to $290^{\circ} \mathrm{C}$ at a rate of $2.5^{\circ} \mathrm{C} \mathrm{min}^{-1}$ with an isothermal hold of $10 \mathrm{~min}$. A NIST-MS library and fragmentation patterns were used to recognize the product peaks in the chromatograms.

\section{RESULTS AND DISCUSSION}

\section{Theoretical basis of catalytic pyrolysis}

The catalyst was used to improve the yield and nature of the liquid product and to shorten the time of reaction to save time and energy. Each catalyst was of clay origin and made of aluminosilicates. The catalysts were prepared at high temperature by extensive dehydration reaction for the formation of polyaluminosilicates. These catalysts were highly porous, with the pores having characteristic electrostatic forces due to the presence of silicate ions and alunimnosilicate backbones. These pores were of molecular dimensions and can be termed as electrostatically active molecular holes or sieves. It reveals that the porous structure of the catalyst may play an important role in increasing its capacity to facilitate the cracking of the pyrolysate. The electrostatic force and unique structural features of the catalysts were responsible for holding the oxygen moieties to avoid development of the water oxygenated compounds. Since catalysts were the clinkered material, they were able to stabilize the alkyl radicals and promote the hydrocarbon formation. This ability of the clinker may be due to its highly porous nature, polyalumionosilicate skeleton and presence of transition metal oxides. Such chemical compositions provide vacant orbital and molecular holes that allow the clinker to maintain the active oxygen moieties and to convert the carbon molecules into hydrocarbon compounds and other less oxygenated compounds of less viscous nature and higher calorific values. Oxygenated compounds have low calorific value in the event of non-catalytic pyrolysis of waste fat oil. Due to the existence of free radical moieties, such compounds promote char formation during combustion in engines. A change in viscosity of fuel is also expected due to presence of these compounds.

\section{Effect of process temperature on pyrolysis of spent fat oil}

Since pyrolysis of biomass depends on the process temperature, any chance in temperature would directly affect the product nature, performance of the pyrolysis process, reaction rate and catalytic activity of the catalyst (Efika et al., 2019; Garcia-Perez et al., 2008). With a change in the temperature of the pyrolysis process, not only the nature of the products but their relative quantity may also differ (Akhtar and Aimn, 2012). The dependence of catalytic activity of the catalyst on temperature is attributed to the temperature dependent energies of the active sites and free energy of the system. Free energy is accountable for change 
in response and number of active sites of the catalyst (Balcik-Canbolat et al., 2017). In case of solid catalyst like clinker and cement, temperature controls the activation energy and catalytic response of the catalyst.

Many scientists are exploring the impact of temperature on yield, nature and relative amount of the products obtained through pyrolysis of synthetic polymers and plastics (Akhtar and Aimn, 2012; BalcikCanbolat et al., 2017; Garcia et al., 1999; Demirbas, 2006; Wan et al. 2009). Demirbas (2006) explored the influence of temperature on relative quantity of the liquid products obtained during biomass pyrolysis. Chemical composition and yield of the the products varied with temperature of the pyrolysis. Considering the results of previous studies, two sets of experiments, i.e. thermal degradation and thermo-catalytic degradation, were performed to optimize the temperature for pyrolysis of wasted fat oil. Cracking through thermo-catalytic process was further split into three sets. Using cement, white cement and clinker as a catalyst, each set of experiments was performed to produce the liquid and gaseous fuels. All tests were conducted by blending 3:1 proportion of fat oil with catalyst and 1 hour heating of the blend. Each experiment was conducted in triplicate and the measurements were averaged. The results of these investigations are presented in Fig. 2. From the outcomes, it can be noted that noncatalytic pyrolysis of fat oil yields substantial residue at $300^{\circ} \mathrm{C}$ and $400^{\circ} \mathrm{C}$; however, catalytic pyrolysis does not produce any residue by demonstrating 100\% transformation of the spent oil into combustible liquid and gas. Complete transformation of fat oil into lighter oil and gas during slow pyrolysis stage shows high catalytic activity of the catalyst. During non-catalytic pyrolysis, the formation of char and chary residue was due to the secondary and tertiary pyrolysis of the pyrolysate, which yields higher amounts of char as a residue. At higher temperatures, the liquid products distill away without undergoing extensive dehydration and forming char.

Since this research focused primarily on converting waste fat oil into hydrocarbon-like lighter oil, the findings indicate that cement catalyst yields comparatively higher oil while clinker yields higher gas amounts. Such catalyst behavior can be described by considering its chemical character, structure and surface morphology. All of these catalysts have clay and calcareous origin. The difference is in relative proportion of various chemicals and the temperature of clinkerization. Clinker or burnt brick powder catalyst is formed by extensive dehydration at as high a temperature as $1500-1700^{\circ} \mathrm{C}$, which forms structurally and chemically different moieties even from the same starting materials. This is because of the partial vitreous nature of the clinker, which is unable to hold and condense the reactive moieties. This is the reason for production of large quantities of gas during
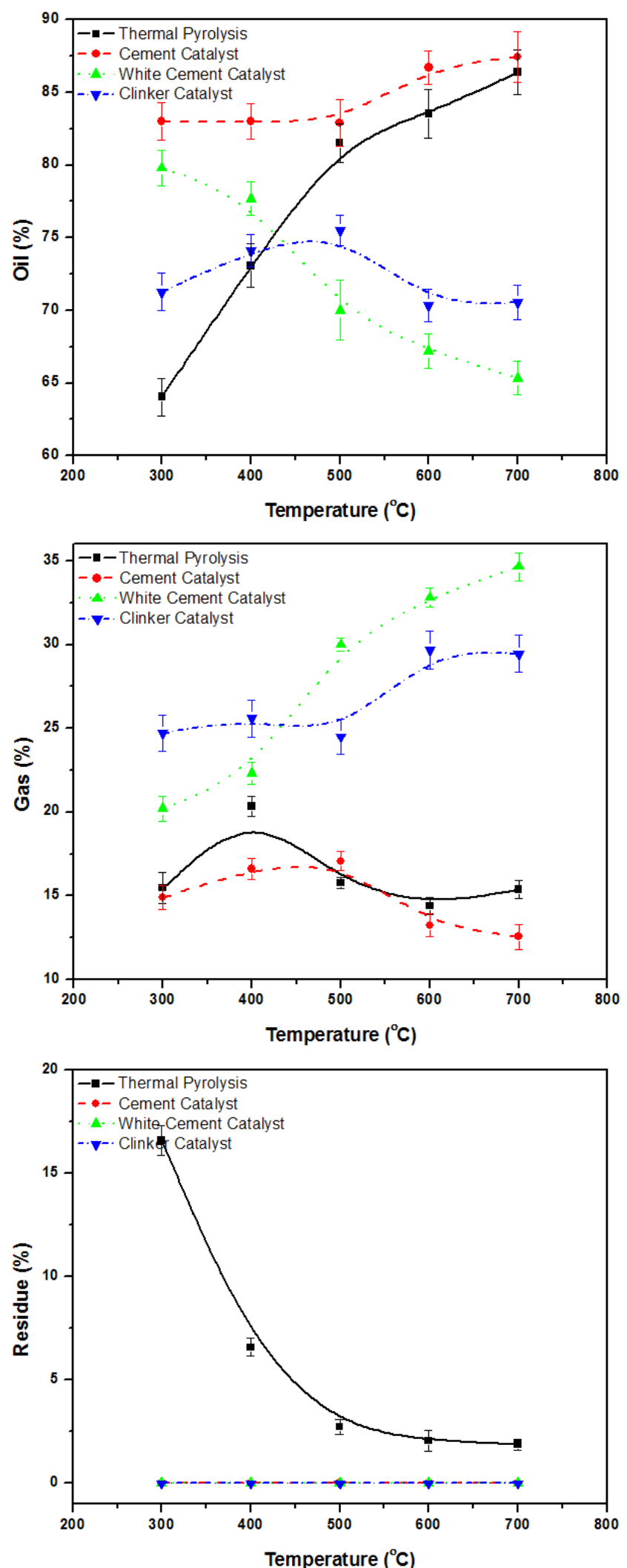

Figure 2. Effect of temperature on thermal and thermocatalytic pyrolysis of spent fat oil.

pyrolysis. In the case of cement, the highly porous and non-vitreous nature of the catalyst helps to convert the reactive moieties into liquid fuel. The ordinary cement 
and white cement catalysts were rich in iron oxide and calcium oxide, respectively. Having different oxides in their compositions, these catalysts produce different fuel phases during pyrolysis. From the results, it can be concluded that all catalysts play a significant part in enhancing the quantity of oil and gas compared to the non-catalytic pyrolysis. These catalysts significantly lower the residue even at temperatures designated for slow pyrolysis. Furthermore, product selectivity is also feasible through the introduction of suitable catalysts and the selection of optimal reaction conditions. White cement and clinker encourage gaseous products while ordinary cement increases the oil concentration. Since $600^{\circ} \mathrm{C}$ process temperature yields negligible amount of the residue during non-catalytic pyrolysis, this temperature was chosen for further studies as the optimum temperature.

\section{Effect of process time}

The impact of process time on pyrolysis has been explored in the range of 15-75 min. Cement catalyst and spent oil were blended in a 1:3: ratio and heated at $600^{\circ} \mathrm{C}$ in a furnace. Fig. 3 shows a comparison of pyrolysis reactions performed with and without a catalyst. The reaction progress was examined in terms of oil quantity and residue. Large quantity of oil product with minimum residue indicates the effectiveness of the reaction. From the plots, it can be seen that the quantity of residue in each reaction reduces as process time increases. Also, catalytic pyrolysis performed much better than the pyrolysis without using a catalyst. In the catalytic pyrolysis, the amount of the residue reaches zero after $30 \mathrm{~min}$ of reaction. In case of the non-catalyzed reaction, the residue did not reach zero even after the maximum tested time. It has also been noted that various catalysts demonstrate different efficiencies during catalytic pyrolysis. Cement was revealed as best catalyst among all the tested catalysts in terms of residue and liquid fuels. Even after 30 min, the pyrolysis reaction catalyzed with cement led in insignificant residue and maximum oil quantity. The residue attained a minimum value after $45 \mathrm{~min}$ of reaction time for both catalyzed and conventional pyrolysis reactions. This process time was stated as the optimum condition for the present work. It is worth noting that the waste fat oil was less volatile than the lighter oil product. It shows that there was primarily a reaction towards pyrolysis rather than a basic distillation process. White cement performed well as a catalyst and produced more oil compared to clinker catalyzed pyrolysis. In terms of percentage conversion efficiency, the pyrolysis reaction catalyzed with clinker performed much better than the noncatalyzed reaction. However, Fig. 3 shows that the clinker catalyzed reaction produces less oil and more gases.
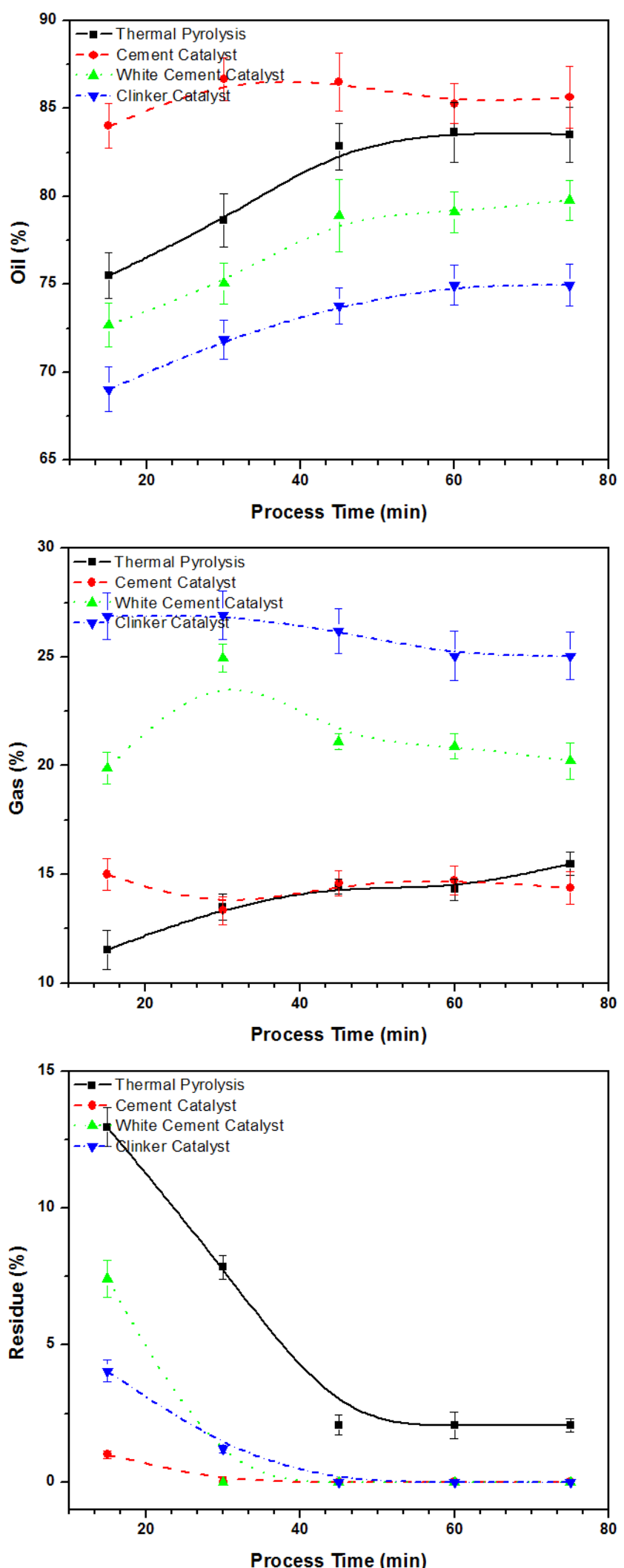

Figure 3. Comparison of process time for catalyzed and non-catalyzed pyrolysis of waste fat oil.

\section{Effect of catalyst weight}

Catalysts are used in most pyrolytic reactions to alter the nature and output of the reaction (Wan et 
al., 2009; Garcia et al., 1999). Changing the catalyst quantity can have a significant impact on the overall efficiency of the reaction. In the present study, the catalyst type and weight influenced the progress of the pyrolysis reaction and product selectivity (Horne et al., 1996). Variation in catalyst weight changes the number of active sites on the catalysis surface. Therefore, investigation of the optimum amount of catalyst may help to enhance the yield and nature of the products in addition to improving the kinetics of the reaction. Use of optimized quantity of the catalyst significantly reduced the formation of char during pyrolysis. Some past reports have revealed the conversion of vegetable oils into liquid and gaseous fuels through catalyst pyrolysis, for example, zeolite has been used as catalyst in a variety of pyrolyses (Xu et al., 2010; Jęczmionek and Porzycka-Semczuk, 2013). (Chew and Bhatia (2009) used sodium carbonate and mesoporous catalyst for catalytic pyrolysis of palm oil into hydrocarbons. In the present study, spent fat oil was converted into liquid and gaseous fuels by changing the relative mass ratios of ordinary Portland cement, white cement and clinker. The pyrolysis reactions were carried out for $45 \mathrm{~min}$ at a fixed process temperature of at $600^{\circ} \mathrm{C}$. The results are summarized in Table 2.

Different parameters were measured including oil amount, residue and gases. However, the progress of the reaction was evaluated by noting the maximum amount of the oil. Almost zero residue was observed in reactions catalyzed with different catalyst concentrations. It reveals that the conversion of the spent fat oil into useful products is almost $100 \%$. Also, selection of the optimum weight of the catalyst was the key factor for maximum conversion. Table 2 demonstrates that for the current study, 5 percent relative weight of the catalyst can be regarded as the optimal situation. However, different catalysts produced different quantities of the oil. Best results were obtained with cement catalyst pyrolysis followed by clinker catalyzed and white cement catalyzed reactions. Presence of ferrites and ferrates in the catalyst reduce the formation of organic compounds and hydrogen gas and water splitting (Markó et al., 1981; Scheffe, 2010; Hussain et al., 2016). The cement catalyzed pyrolysis produced the largest amount of the oil, which is ascribed to the hydrogenations, presence of alkyl radicals and holding of organic moieties. White cement, unlike ordinary Portland cement, was rich in lime and contained small percentage of iron compounds. This catalyst has excellent ability not to form the oil, but to crack and gasify the feedstock. In case of clinker, the vitrified sites of catalyst may be responsible for preferable gasification as compared to ordinary cement (Hussain et al., 2016).

\section{Physical characteristics of the oil product}

Unlike the starting material, at ambient temperature, the oil product existed in liquid form. At ambient temperature, the starting material was semi-solid, black in the waste form and white or pearl white in virgin state. The colour of the oil product of both catalytic and non-catalytic pyrolysis was brownish yellow. The viscous oil product was formed of volatile and nonvolatile compounds. By fractional distillation, the oil product could be separated into gasoline and diesel-like oils. A laboratory-scale distillation device was used to separate $100 \mathrm{ml}$ of the oil product into its components. The results of the fractional distillation test are given in Table 3. Each oil sample revealed a unique distillation profile, depending on the catalyst type. A change in chemical composition of the oil product with catalyst type is supportive to our assumption that it is possible to control the product selectivity through deliberately choosing the catalyst. The product of conventional pyrolysis was non-volatile and contained diesel and kerosene. The non-catalytic pyrolysis generated $56 \%$ residue whereas the clinker catalyzed reaction generated only $32 \%$ residue.

Table 3 also contains information on relative amounts and boiling points of the oil fractions. The

Table 3. Distillation profiles of the oil product.

\begin{tabular}{ccccc}
\hline Temperature & \multicolumn{4}{c}{ Volume of the distillate (mL) } \\
\cline { 2 - 5 }$\left({ }^{\circ} \mathbf{C}\right)$ & T & C & W. C. & Cl \\
\hline 80 & --- & 10.0 & --- & --- \\
90 & --- & 8.0 & -- & --- \\
100 & --- & 15.0 & --- & --- \\
110 & 5.5 & --- & --- & 11 \\
120 & --- & 20.5 & 15.0 & --- \\
150 & 13.5 & --- & -- & 16 \\
180 & 8.0 & 10.5 & 20.0 & --- \\
240 & 10.0 & --- & 25.0 & 18 \\
250 & 7.0 & --- & --- & 22 \\
\hline
\end{tabular}

Table 2. Investigation of optimum weight of catalyst for the pyrolysis of waste fat oil.

\begin{tabular}{cccccccccc}
\hline \multirow{2}{*}{$\begin{array}{c}\text { \% Weight } \\
\text { of catalyst }\end{array}$} & \multicolumn{3}{c}{ Oil (\%) } & \multicolumn{3}{c}{ Gases (\%) } & \multicolumn{2}{c}{ Residue (\%) } \\
\cline { 2 - 10 } & W.C & Cl & C & W.C & Cl & C & W.C & Cl \\
\hline 5 & 84.52 & 78.32 & 81.94 & 15.47 & 21.68 & 17.10 & 0.00 & 0.00 & 0.00 \\
10 & 81.61 & 76.45 & 81.22 & 18.38 & 23.55 & 18.77 & 0.00 & 0.00 & 0.00 \\
20 & 72.18 & 73.57 & 72.87 & 27.75 & 26.43 & 27.12 & 0.00 & 0.00 & 0.00 \\
30 & 71.37 & 70.00 & 69.00 & 28.63 & 30.00 & 31.00 & 0.00 & 0.00 & 0.00 \\
40 & 64.6 & 68.54 & 63.33 & 35.4 & 31.46 & 36.66 & 0.00 & 0.00 & 0.00 \\
50 & 61.25 & 62.30 & 54.5 & 38.75 & 37.7 & 45.5 & 0.00 & 0.00 & 0.00 \\
\hline
\end{tabular}

Abbreviations: $\mathrm{C}=$ Cement, W.C $=$ White cement, $\mathrm{Cl}=$ Clinker. 
quantity of fractions with low boiling point stayed small compared to the other components of the oil obtained through cement catalyzed pyrolysis. The distillate and residue quantities were measured about $64 \%$ and $36 \%$, respectively. The residue was azeotropic and composed of fractions having different boiling points. It was assumed that residue undergoes thermal decomposition and forms volatile fractions in the temperature range of $240-260^{\circ} \mathrm{C}$. The white cement catalyzed reaction yielded very few fractions with low boiling points. In white cement catalyzed pyrolysis, the amount of distillate and residue remained $60 \%$ and $40 \%$, respectively. The residue cracked into volatile oil and gas on heating at temperatures in the range of $240-260^{\circ} \mathrm{C}$. Similarly, the clinker catalyzed reaction yielded $32 \%$ residue and $67 \%$ distillate. The residue of clinker catalyzed reaction was azeotropic in nature and composed of fractions of mixed boiling points.

\section{GC-MS study of the oil product}

GC-MS technique was used to analyze the oil products of both catalyzed and conventional pyrolysis reactions. The results of this study are shown in Table 4. The cement, white cement and clinker catalyzed pyrolysis reactions produced oils with $19.893 \%$, $51.177 \%$ and $93.911 \%$ hydrocarbons, respectively. The relative concentration of oxygenated compounds in the oil products of these reactions was measured about $80.107 \%, 48.823 \%$ and $6.089 \%$, respectively. However, only $3.122 \%$ hydrocarbons were noticed in the oil product of the conventional pyrolysis, which were mostly fatty acids. The octadec-9-enoic acid and octadecanoic acid were measured about $12.836 \%$ and $21.737 \%$, respectively. The oil product of cement and clinker catalyzed reactions contained only esters, whereas the oil product of white cement catalyzed reaction gave $8.34 \%$ octadecanoic acid. This reflects that the catalyst in the reaction promotes the formation of hydrocarbons and suppresses the oxygen content. Additionally, catalyst raises the number of esters and reduces the amount of carboxylic acid. A decrease in carboxylic acids might be due to the presence of solid oxides in the catalyst. Clinker catalyst was found more effective among all the tested catalysts in terms of lowering the oxygen content.

\section{Combustibility test of gas product}

The gases, produced during pyrolysis, were assumed highly combustible. A miniature burner was used to test these gases for their combustibility. The gases were not tested quantitatively, but their chemical nature was studied through qualitative chemical analysis. The gas samples were passed through chemical trapes and tested for alkynes. An aqueous solution of ammoniacal cuprous chloride was used to serve the purpose. This is a characteristic test for identification of acetylene in the product. The formation of acetylene was expected due to dehydration and dehydrogenation reactions. The olefins in the product were identified using bromine water and Baeyer's testing. In Baeyer's test, an aqueous solution of potassium permanganate was used to identify alkene and aldehyde gases. For qualitative analysis, the solutions were placed in series after the cold traps. In this test, the gaseous product of each pyrolysis reaction formed some red precipitate, which shows the presence of acetylene in the product. The colour of the bromine water and potassium permanganate solution was changed on the gas through them. It shows that the gaseous product was composed of unsaturated hydrocarbons, alkenes and formaldehyde.

Table 4. GC-MS profiles of the oil product.

\begin{tabular}{|c|c|c|c|c|c|c|}
\hline \multirow{2}{*}{$\begin{array}{c}\text { RT } \\
(\text { min) }\end{array}$} & \multirow{2}{*}{ Name } & \multirow{2}{*}{ Mol. Weight } & \multicolumn{4}{|c|}{ Relative \% concentration } \\
\hline & & & $\mathbf{T}$ & $\mathrm{C}$ & W. C. & $\mathrm{Cl}$ \\
\hline 5.594 & 2-Heptadecanol & 256.277 & --- & --- & 19.412 & --- \\
\hline 6.531 & 10-Heneicosene & 294.329 & --- & 18.032 & --- & --- \\
\hline 6.555 & 5-Nonadecene & 266.297 & --- & --- & 8.84 & --- \\
\hline 6.555 & Nonadecane & 268.313 & --- & --- & --- & 17.606 \\
\hline 6.647 & Methyl Palmitate & 256.24 & 36.579 & --- & --- & --- \\
\hline 10.216 & 2-Nonadecanone & 282.292 & --- & 8.544 & --- & 19.627 \\
\hline 11.339 & Octadec-9-enoic acid & 282.256 & 12.836 & --- & --- & --- \\
\hline 12.327 & Dihexyl fumarate & 284.272 & --- & 26.595 & --- & --- \\
\hline 12.483 & Octadecanoic acid & 284.1 & 21.737 & -- & 8.34 & --- \\
\hline 13.942 & 1-Docosene & 308.344 & -- & --- & 8.145 & --- \\
\hline 25.985 & Hexanedioic acid, mono(2-thylhexyl)ester & 258.183 & --- & 44.968 & --- & --- \\
\hline 26.702 & Furan-2-ylmethyl palmitate & 336.507 & 25.573 & --- & --- & --- \\
\hline 27.652 & Cyclotetracosane & 336.376 & --- & --- & 12.189 & 62.327 \\
\hline 36.086 & Tetracosane & 338.391 & --- & --- & 4.265 & -- \\
\hline 47.599 & 1,1'-Bicyclopentyl, 2-hexadecyl- & 362.391 & --- & --- & 2.676 & --- \\
\hline 51.442 & 5-Eicosene, $(\mathrm{E})-$ & 280.313 & --- & 1.861 & --- & --- \\
\hline 51.461 & 9-Hexacosene & 364.407 & 3.122 & --- & --- & --- \\
\hline 52.926 & 9-Hexacosene & 364.407 & --- & --- & --- & 13.978 \\
\hline 53.103 & 1-Hexacosene & 364.407 & --- & --- & 16.507 & --- \\
\hline
\end{tabular}




\section{CONCLUSIONS}

The spent fat oil is successfully converted into liquid and gaseous fuels through catalytic and noncatalytic pyrolysis in a batch type reactor. Cement, white cement and clinker were tested as catalysts for catalytic conversion of the spent fat oil. The cement as a catalyst produces larger quantities of oil, whereas clinker and white cement catalysts encourage the formation of larger quantities of the gaseous products. Other than the product selectivity, the used catalysts also accelerated the reaction speed by reducing the pyrolysis time from $60 \mathrm{~min}$ to $45 \mathrm{~min}$. Almost zero residue was observed after catalytic pyrolysis time of $45 \mathrm{~min}$. The conventional pyrolysis yielded $3 \%$ only hydrocarbons, whereas cement catalyzed reaction produced $19 \%$ hydrocarbons. White cement and clinker catalyzed reactions produced $51 \%$ and $93 \%$ hydrocarbons, respectively. The oil product of conventional pyrolysis was mainly composed of fatty acids, such as octadec-9-enoic acid and octadecanoic acid. The cement catalyzed pyrolysis yielded only esters, the white cement catalyzed pyrolysis yielded only one fatty acid and the clinker catalyzed pyrolysis yielded only ester but no fatty acids.

\section{REFERENCES}

Adebanjo, A.O., Dalai, A.K., Bakhshi, N.N. Production of diesel-like fuel and other value-added chemicals from pyrolysis of animal fat. Energy \& Fuels, 19, 1735-1741 (2005). https://doi.org/10.1021/ ef040091b

Akhtar, J., Amin, N.S. A review on operating parameters for optimum liquid oil yield in biomass pyrolysis. Renewable and Sustainable Energy Reviews, 16, 5101-5109 (2012). https://doi.org/10.1016/j. rser.2012.05.033

Ali, N., Chaudhary, B. L., Panwar, N. L. The Fungal PreTreatment of Maize Cob Heart and Water Hyacinth for Enhanced Biomethanation, International Journal of Green Energy, 11, $40-49$ (2014). https://doi.org/1 0.1080/15435075.2012.740707

Balcik-Canbolat, C., Ozbey, B., Dizge, N., Keskinler, B. Pyrolysis of commingled waste textile fibers in a batch reactor: Analysis of the pyrolysis gases and solid product, International Journal of Green Energy, 14, 289-294 (2017). https://doi.org/10.108 0/15435075.2016.1255634

Buscato, M.H.M., Zaia, B.G., Godoi, K.R.R. de, Ribeiro, A.P.B., Kieckbusch, T.G. Modification of palm oil crystallization by phytosterol addition as a tool for structuring a low saturated lipid blend, Brazilian Journal of Chemical Engineering, 3,169-180 (2018). https://doi.org/10.1590/0104$6632.20180351 \mathrm{~s} 20160351$
Chew, T.L., Bhatia, S. Effect of catalyst additives on the production of biofuels from palm oil cracking in a transport riser reactor. Bioresource Technology, 100, 2540-2545 (2009). https://doi.org/10.1016/j. biortech.2008.12.021

Demirbaş, A. Oily products from mosses and algae via pyrolysis. Energy Sources, Part A, 28, 933-940 (2006). https://doi.org/10.1080/009083190910389

Efika, C.E., Onwudili, J.A., Williams, P.T. Influence of heating rates on the products of hightemperature pyrolysis of waste wood pellets and biomass model compounds. Waste Management, 76, 497-506 (2018). https://doi.org/10.1016/j. wasman.2018.03.021

Garcia, L., Salvador, M.L., Arauzo, J., Bilbao, R., Catalytic steam gasification of pine sawdust. Effect of catalyst weight/biomass flow rate and steam/ biomass ratios on gas production and composition. Energy \& Fuels, 13, 851-859 (1999). https://doi. org/10.1021/ef980250p

Garcia-Perez, M., Wang, X.S., Shen, J., Rhodes, M.J., Tian, F., Lee, W.J., Wu, H., Li, C.Z. Fast pyrolysis of oil mallee woody biomass: effect of temperature on the yield and quality of pyrolysis products. Industrial \& Engineering Chemistry Research, 47, 1846-1854 (2008). https://doi.org/10.1021/ ie $071497 \mathrm{p}$

Horne, P.A., Williams, P.T. Upgrading of biomassderived pyrolytic vapours over zeolite ZSM-5 catalyst: effect of catalyst dilution on product yields. Fuel, 75, 1043-1050 (1996). https://doi. org/10.1016/0016-2361(96)00082-8

Hussain, Z., Sulaiman, S.A., Khan, A., Khan, K.M., Perveen, S., Naz, M.Y. Two-Step Pyrolysis of Spirogyra for Fuels Using Cement Catalytic. Waste and Biomass Valorization, 7, 1481-1489 (2016). https://doi.org/10.1007/s12649-016-9552-y

Hussain, Z., Sulaiman, S.A., Gul, H., Farooq, S., Khan, K.M., Gulab, H., Naz, M.Y. Conversion of waste-soap and soap-like materials into diesel and gasoline by catalytic pyrolysis using virgin soap as model. The Canadian Journal of Chemical Engineering, 94, 94-100 (2016). https://doi. org/10.1002/cjce.22368

Jęczmionek, Ł., Porzycka-Semczuk, K. Triglyceride zeoforming-A method for improving the lowtemperature properties of second generation biocomponents obtained from natural oils. Fuel, 113, 17-23 (2013). https://doi.org/10.1016/j. fuel.2013.05.012

Kalam, M.A., Masjuki, H.H., Jayed, M.H., Liaquat, A.M. Emission and performance characteristics of an indirect ignition diesel engine fuelled with waste cooking oil. Energy, 36, 397-402 (2011). https:// doi.org/10.1016/j.energy.2010.10.026 
Kulkarni, M.G., Dalai, A.K. Waste cooking oil an economical source for biodiesel: a review. Industrial \& Engineering Chemistry Research, 45, 2901-2913 (2006). https://doi.org/10.1021/ie0510526

Markó, L., Radhi, M.A., Ötvös, I. Catalytic and stoichiometric reduction of ketones and aldehydes by the hydridotetracarbonyl ferrate anion. Journal of Organometallic Chemistry, 218, 369-376 (1981). https://doi.org/10.1016/S0022-328X(00)81009-8

Quirino, R.L., Tavares, A.P., Peres, A.C., Rubim, J.C., Suarez, P.A. Studying the influence of alumina catalysts doped with tin and zinc oxides in the soybean oil pyrolysis reaction. Journal of the American Oil Chemists' Society, 86, 167 (2009). https://doi.org/10.1007/s11746-008-1331-x

Scheffe, J.R., Li, J., Weimer, A.W. A spinel ferrite/ hercynite water-splitting redox cycle. International Journal of Hydrogen Energy, 35, 3333-3340 (2010). https://doi.org/10.1016/j.ijhydene.2010.01.140

Souza, M.F., Francisco, C.R.L., Sanchez, J.L., Guimarães-Inácio, A., Valderrama, P., Bona, E., Tanamati, A.A.C., Leimann, F.V., Gonçalves, O.H. Fatty acids profile of chia oil-loaded lipid microparticles, Brazilian Journal of Chemical Engineering, 34, 659-669 (2017). https://doi. org/10.1590/0104-6632.20170343s20150669

Totani, N., Yamaguchi, A., Takada, M., Moriya M., Color deterioration of oil during frying. Journal of Oleo Science, 55, 51-57 (2006). https://doi. org/10.5650/jos.55.51

Wan, Y., Chen, P., Zhang, B., Yang, C., Liu, Y., Lin, X., Ruan, R. Microwave-assisted pyrolysis of biomass: Catalysts to improve product selectivity. Journal of Analytical and Applied Pyrolysis, 86, 161-167 (2009). https://doi.org/10.1016/j.jaap.2009.05.006

Xu, J., Jiang, J., Sun, Y., Chen, J. Production of hydrocarbon fuels from pyrolysis of soybean oils using a basic catalyst. Bioresource Technology, 101, 9803-9806 (2010). https://doi.org/10.1016/j. biortech.2010.06.147

Yang, H.H., Chien, S.M., Lo, M.Y., Lan, J.C.W., Lu, W.C., $\mathrm{Ku}$, Y.Y. Effects of biodiesel on emissions of regulated air pollutants and polycyclic aromatic hydrocarbons under engine durability testing. Atmospheric Environment, 41, $7232-7240$ (2007). https://doi.org/10.1016/j.atmosenv.2007.05.019 
